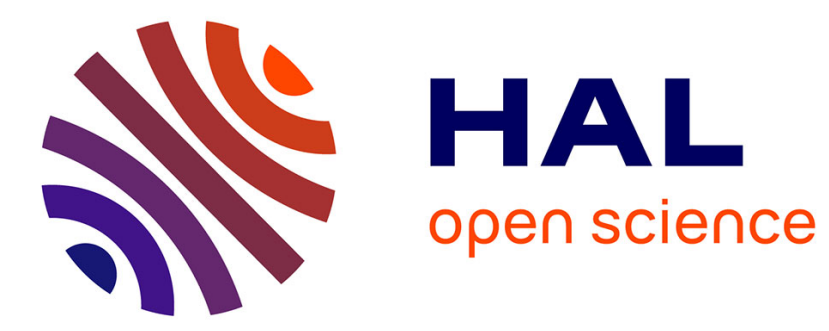

\title{
Seven compounds from Portulaca oleracea L. and their anticholinesterase activities
}

Wen Xu, Jianhua Wang, Baozhao Ju, Xiujuan Lan, Xixiang Ying, Didier Stien

\section{To cite this version:}

Wen Xu, Jianhua Wang, Baozhao Ju, Xiujuan Lan, Xixiang Ying, et al.. Seven compounds from Portulaca oleracea L. and their anticholinesterase activities. Natural Product Research, inPress, 36, pp.2547-2553. 10.1080/14786419.2021.1916928 . hal-03216986

\section{HAL Id: hal-03216986 https://hal.science/hal-03216986}

Submitted on 4 May 2021

HAL is a multi-disciplinary open access archive for the deposit and dissemination of scientific research documents, whether they are published or not. The documents may come from teaching and research institutions in France or abroad, or from public or private research centers.
L'archive ouverte pluridisciplinaire HAL, est destinée au dépôt et à la diffusion de documents scientifiques de niveau recherche, publiés ou non, émanant des établissements d'enseignement et de recherche français ou étrangers, des laboratoires publics ou privés. 
1 Seven compounds from Portulaca oleracea L. and their anticholinesterase

2 activities

3 Wen $\mathrm{Xu}^{\mathrm{a}, \dagger}$, Jianhua Wang ${ }^{\mathrm{b}, \dagger}$, Baozhao $\mathrm{Ju}^{\mathrm{b}}$, Xiujuan Lan $^{\mathrm{a}}$, Xixiang Ying ${ }^{\mathrm{a}, *}$ and

$4 \quad$ Didier Stien $^{\mathrm{c}, *}$

5 Affiliation

6 a School of Pharmacy, Liaoning University of Traditional Chinese Medicine, Dalian,

7 China

$8 \quad{ }^{\mathrm{b}}$ School of Traditional Chinese Medicine, Liaoning University of Traditional Chinese

9 Medicine, Shenyang, China

$10{ }^{\mathrm{c}}$ Sorbonne Université, CNRS, Laboratoire de Biodiversité et Biotechnologie

11 Microbiennes (LBBM), Observatoire Océanologique, Banyuls-sur-Mer, France

12 E-mail address in order: xuwen199654@163.com,wjh-1985@163.com,jubaozhao@163.com, xiujuanlan@139.com, yingxixiang@163.com, and didier.stien@cnrs.fr

\section{*Correspondence}

Correspondence author: Prof. Xixiang Ying, School of Pharmacy, Liaoning University of Traditional Chinese Medicine, No.77, Shengming 1 Road, DD Port, Dalian, 116600, P.R. China, Tel: +86-0411-85890139, Fax: +86-0411-85890128, yingxixiang@163.com

Correspondence author: Dr. Didier Stien, Sorbonne Université, CNRS, Laboratoire de Biodiversité et Biotechnologie Microbiennes, LBBM, Observatoire Océanologique, 66650 Banyuls-sur-Mer, France, Tel: +33-430192476, didier.stien@cnrs.fr

${ }^{\dagger}$ Wen Xu and Jianhua Wang contributed equally to this work. 


\section{Abstract}

27

novel

lignan,

identified

as

28

4-(3,4-dihydroxyphenyl)-6,7-dimethoxy-3a,4-dihydronaphtho[2,3-c]furan-1(3H)-one, named oleralignan A (1), together with six known compounds, loliolide (2), isololiolide (3), dehydrololiolide (4), daphnetin (5), esculetin (6), and trans-coumaric acid methyl ester (7) was obtained from Portulaca oleracea L., while compounds $\mathbf{3}, \mathbf{4}$, and 6-7 were isolated from the plant for the first time. Their structures were elucidated using spectroscopic methods, including one- and two-dimensional NMR and high-resolution electrospray ionization time-of-flight mass spectrometry. In addition, the results of activity assay demonstrated that compounds 1-7 have anticholinesterase activities.

Keywords: Portulaca oleracea L.; lignan; isolation; anticholinesterase activity 


\section{Introduction}

Portulaca oleracea L., an annual green herb, belonging to the family of Portulacaceae, with branched and succulent stems, is edible and has a slightly acidic and salty taste similar to spinach (Lim and Quah 2007). It is consumed as a vegetable and has been reported to provide better nutrition than the major cultivated vegetables (Yazici et al. 2007). It is widely distributed in Africa, China, India, Australia, Middle East, Europe and America (Rashed et al. 2003). It has been listed by the World Health Organization as one of the most used medicinal plants and has been given the term 'Global Panacea' (Zheng et al. 2017). As a traditional Chinese medicine, it is well-known as diuretic, febrifuge, antiseptic, antispasmodic and vermifuge (Shen et al. 2013). At the same time, $P$. oleracea $L$. has been reported to possess a wide variety of pharmacological effects, such as anti-inflammatory (Meng et al. 2016), antibacterial (Nayaka et al. 2014), antiulcerogenic (Karimi et al. 2004), antitumor (Shen et al. 2013), antioxidant (Yang et al. 2019), antidiabetic (Bai et al. 2016), or anticholinesterase (Xiu et al. 2019), among others. These activities have been related to its chemical constituents including alkaloids (Zhao et al. 2019), flavonoids (Yang et al. 2018), lignans (Ma et al. 2018), fatty acids (Teixeira et al. 2010), or minerals (Uddin et al. 2012). In the present work, we isolated 7 intersting compounds from $P$. oleracea L. including 1 new arylnaphthalene lignan containing 2 methoxy groups. At the same time, some lignans have been reported to have anticholinesterase activity, and the methoxy group in lignans can effectively enhance its anticholinesterase effect (Salleh et al. 2016). However, study on the anticholinesterase activity of arylnaphthalene lignans has not been found. Therefore, we undertook to evaluate their anticholinesterase activities following the modified Ellman's method.

\section{Results and discussion}

\subsection{Structure elucidation}

Compound 1, a yellowish powder, has the molecular formula $\mathrm{C}_{20} \mathrm{H}_{18} \mathrm{O}_{6}$, as deduced from the HR-ESI-TOF-MS deprotonated molecular ion at $\mathrm{m} / \mathrm{z} 353.1021[\mathrm{M}-\mathrm{H}]^{-}$ (calcd. for $\mathrm{C}_{20} \mathrm{H}_{17} \mathrm{O}_{6}^{-}, 353.1031$ ), corresponding to 12 degrees of unsaturation. The examination of the ${ }^{1} \mathrm{H},{ }^{13} \mathrm{C}$, and HSQC spectra of $\mathbf{1}$ demonstrated that several signals were very broad in ${ }^{1} \mathrm{H}$ and ${ }^{13} \mathrm{C}$ NMR spectra. Some signals were also duplicated. This eventually turned out to originate from the slow rotation of the unsymmetrical phenyl 
<smiles>COc1cc2c(cc1OC)[C@H](c1ccc(O)c(O)c1)[C@H]1COC(=O)C1=C2</smiles>

1

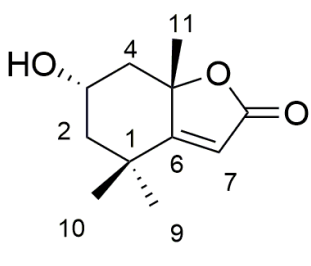

3<smiles>O=c1ccc2cc(O)c(O)cc2o1</smiles>

6

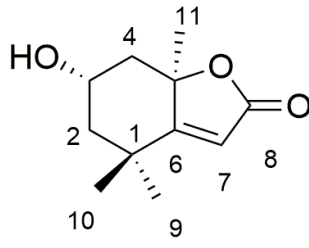

2
77

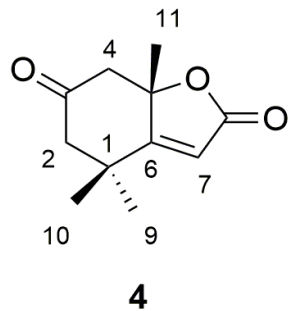<smiles>O=c1ccc2ccc(O)c(O)c2o1</smiles>

5<smiles>COC(=O)/C=C/c1ccc(O)cc1</smiles>

7

\section{Figure 1}

With regard to the structural determination itself, it was possible to establish the presence of a 1,2,4,5-tetrasubstituted benzene ring based on the signals of protons $\mathrm{H}-5$ $\left(\delta_{\mathrm{H}} 6.16\right)$ and $\mathrm{H}-8\left(\delta_{\mathrm{H}} 7.16\right)$ together with their respective carbons at $\delta_{\mathrm{C}} 114.9$ and 113.9 and their HMBC correlations with non-protonated carbons of the benzene ring (Table S1 in supplementary material, Figure 2). Since protons H-5 and H-8 correlated with both C-6 and C-7, the assignment of both methoxy groups was based on the COSY and ROESY correlations of MeO-C7 with $\mathrm{H}-8$, but also the ROESY correlation of MeO-C6 with H-2'. The COSY and ROESY spectra also provided key information regarding the substituents in positions $4 \mathrm{a}$ and $8 \mathrm{a}$. Thanks to these data, it 
was possible to position $\mathrm{H}-4$ close to $\mathrm{H}-5$ and $\mathrm{H}-9$ close to $\mathrm{H}-8$. This was confirmed by the HMBC correlations of H-4 with C-4a and C-8a and of H-9 with C-4a, C-8a and $\mathrm{C}-8$. The COSY spectrum defined a proton sequence $\mathrm{H}-4 / \mathrm{H}-3 \mathrm{a} / \mathrm{H}-3$, and the proton and carbon chemical shifts in position $3\left(\delta_{\mathrm{H}} 3.97 / 4.33, \delta_{\mathrm{C}} 71.5\right)$ demonstrated that C-3 was link to an oxygen. The HMBC correlations H-9/C-3a, H-9/C-1, and H-3-y/C-1 completed the 3a,4-dihydroisobenzofuran-1-one subunit.
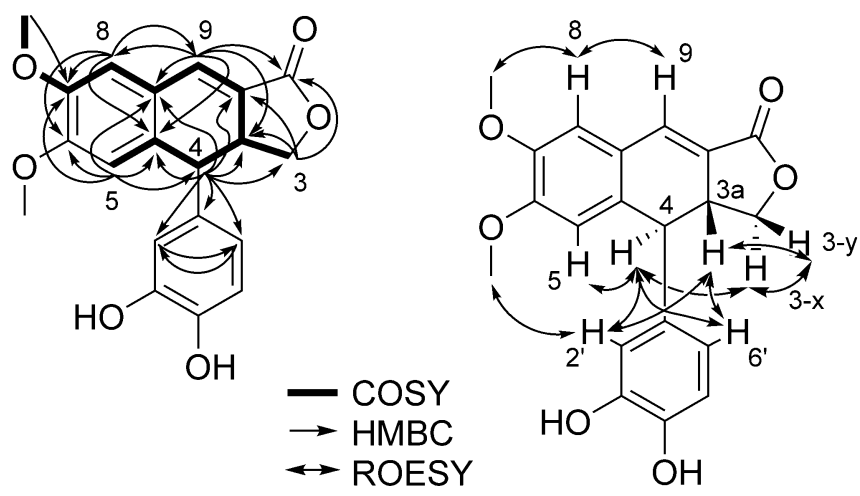

Figure 2

Additional correlations of $\mathrm{H}-4$ with $\mathrm{C}-1^{\prime}, \mathrm{C}-2^{\prime}$ and $\mathrm{C}-6$ ' demonstrated that an aromatic ring was linked to C-4 and that both ortho positions were protonated. The fact that the signals are very wide and are split does not prevent the structural determination because protons H-2' and H-6' also correlated in ROESY with H-3a, H-4 and for H-2', MeO-C6. As the lateral aromatic ring could not be symmetrical, two hydroxy groups had to be positioned on the C-3' and C-4' carbons. The hydroxy protons are visible in ${ }^{1} \mathrm{H}$ NMR at $\delta_{\mathrm{H}} 8.97$ and 9.45. The remaining methine was assigned to position 5'. The relative configuration of compound 1 was ascertained based on the $8.6 \mathrm{~Hz}$ coupling between $\mathrm{H}-3 \mathrm{a}$ and $\mathrm{H}-4$ along with the ROESY correlations $\mathrm{H}-4 / \mathrm{H}-3-\mathrm{x}$ and $\mathrm{H}-3 \mathrm{a} / \mathrm{H}-3-\mathrm{y}$ which were consistent with an anti-periplanar configuration of protons $\mathrm{H}-3 \mathrm{a}$ and $\mathrm{H}-4$. Coupling constants of $8-10 \mathrm{~Hz}$ are found in analogous compounds described in the literature, including conidendrin (Barton 1968; Davies and Jin 2003). Eventually, compound 1 was identified as a conidendrin-related lignan and was given the trivial name oleralignan A.

By comparison of the ${ }^{1} \mathrm{H}$ and ${ }^{13} \mathrm{C}$ NMR spectral data with literature, the 6 known compounds (2-7) were identified, respectively, as loliolide (2) (Mori and Khlebnikov 1993), isololiolide (3) (Zheng et al. 2014), dehydrololiolide (4) (Zheng et al. 2014), 
daphnetin (5) (Xu et al. 2008), esculetin (6) (Zhou et al. 2009), trans-coumaric acid methyl ester (7) (Wan et al. 2012).

\subsection{Anticholinesterase activity}

Alzheimer's disease (AD) is the most common neurodegenerative disorder of aging, accounting approximately for two-third of all cases of senile dementia (Tandon et al. 2000). AD is neurochemically characterised by a consistent deficit in cholinergic neurotransmission, particularly affecting cholinergic neurons in the basal forebrain. Symptoms of $\mathrm{AD}$ and other forms of dementia can be treated by the use of agents which restore the level of acetylcholine through inhibition of both major cholinesterases: acetylcholinesterase and butyrylcholinesterase (Loizzo et al. 2009). Studies have shown that some lignans exhibit neuroprotective effects, increasing choline acetyltransferase activity, inhibiting acetylcholinesterase (AChE) activity in vitro, and increasing hippocampal acetylcholine release in vivo (Howes and Houghton 2003). Consequently, the anticholinesterase activities of the 7 compounds were evaluated using a microplate assay. Oleralignan A (1) inhibited enzyme activity at $58.31 \pm 0.23 \mu \mathrm{M}$. Compounds $\mathbf{2 - 7}$ activity ranged from $71.50 \pm 0.39 \mu \mathrm{M}$ to $93.88 \pm$ $0.39 \mu \mathrm{M}$. Overall, oleralignan A exhibited higher anticholinesterase activity than compounds 2-7(Table S2, in supplementary material).

\section{Experimental}

\subsection{General experimental procedures}

The NMR spectra were obtained using an AVANCE $600 \mathrm{MHz}$ instrument (Bruker Corporation, Switzerland). HRMS was determined using a 6520 quadrupole-time-of-flight mass spectrometer (Agilent, Palo Alto, CA). The UV data was obtained from a HITACHI U-3010 spectrophotometer (Hitachi Ltd, Tokyo, Japan), the IR spectrum and data obtained from IR200 spectrophotometer (Thermo Electron Corporation, Waltham, MA). In the separation process, the $\mathrm{GF}_{254}$ (Qingdao Marine Chemical Co., Qingdao, China) was being as TLC filling, the silica gel (100-200 and 200-300 mesh, Qingdao Marine Chemical Co., Qingdao, China), polyamide resin (80-100 mesh, Taizhou Luqiao Sijia Biochemical Plastic Factory, Zhejiang, China) and ODS (20-40 $\mu \mathrm{m}$, GE Healthcare, Marlborough, MA) were used as column chromatographic filling. The 96-well microplate reader (HBS-1096A) was from Nanjing Detie Experimental Equipment Co., Ltd. (Nanjing, China).

\subsection{Plant materials and chemicals}


The whole herbs of $P$. oleracea L. were collected in Shijiazhuang (Hebei, China) in June 2017, and identified by Prof. Xixiang Ying. The voucher specimens (No. 20171001) were deposited at School of Pharmacy, Liaoning University of Traditional Chinese Medicine. Acetylthiocholine iodide (ATCI) (purity $\geq 99 \%$ ) and AChE (vitality $\geq 200$ units/mg protein) were from Dalian Meilun Biotechnology Co., Ltd. (Dalian, China), 5, 5-dithiobis-2-nitrobenzoic acid (DTNB) (purity $\geq 99 \%$ ) was from Shanghai Jinsui Bio-Technology Co., Ltd. (Shanghai, China) and eserine (purity $\geq$ 98\%) was from Shanghai Hanxiang Biotechnology Co., Ltd. (Shanghai, China). The HPLC grade formic acid, acetonitrile and methanol were purchased from Damao Chemical Reagent Plant (Tianjin, China, purity $\geq 99.9 \%$ ). All other reagents were analytical grade reagents supplied by Jinfeng Chemical Factory (Tianjin, China), and the purified water was from WAHAHA Company (Shenyang, China).

\subsection{Isolation and identification}

The dried whole herb of $P$. oleracea L. $(250 \mathrm{~kg})$ were extracted twice with 10 volumes of water for 2 hours each time, and then the water extract was concentrated to obtain a crude extract $(21 \mathrm{~kg})$, which was subjected to a 100-200 mesh silica-gel column chromatography $(61 \times 55 \mathrm{~cm}$, approximately, $70 \mathrm{~kg})$ with a 2 volumes of ethyl acetate 3 times as the isocratic elution, affording the fraction evaporated $(550 \mathrm{~g})$. Then, the fraction was subjected to the 80-100 mesh polyamide resin column chromatography $(120 \times 8 \mathrm{~cm}$, approximately, $1 \mathrm{~kg})$, eluting with water, 30\%, 50\%, $70 \%$ and $100 \%$ ethanol to obtain five fractions (4 L each). The fraction of $50 \%$ extracting (121 g) was condensed then subjected to a 200-300 mesh silica-gel column $(120 \times 8 \mathrm{~cm}$, approximately, $1 \mathrm{~kg})$ for further purification with ethyl acetate, ethyl acetate and methanol $(5: 1,2: 1, \mathrm{v} / \mathrm{v})$ as the gradient eluant, obtaining three fractions (Frs. 1-3, $4 \mathrm{~L}$ each). The fraction of ethyl acetate (69 $\mathrm{g}$ ) was subjected to the $20-40 \mu \mathrm{m}$ octadecylsilyl (ODS) column chromatography $(25 \times 3 \mathrm{~cm}$, approximately, $150 \mathrm{~g}$, Ultimate XB-C18) with methanol and water (60:40, 70:30, 80:20, 90:10, 100:0, v/v) as the gradient eluant under medium pressure, acquiring five fractions (A1-A5, 500 mL each). Among that, A1 was purified on a Sephadex LH-20 column (100 g, $\varphi 2 \times$ $150 \mathrm{~cm}$ ) using methanol solvent to obtain seven fractions B1-B7, and then these fractions were further prepared by UHPLC, using $\mathrm{MeOH}-0.1 \%$ formic acid as the mobile phase, with flow rate of $1.0 \mathrm{~mL} / \mathrm{min}$, and obtained compound 1 ( $2 \mathrm{mg}$, purity of $>98 \%$ with UHPLC, $t_{R} 13.82 \mathrm{~min}, \mathrm{MeOH}-0.1 \%$ formic acid, 61:39, v/v), 
compound 2 ( $2 \mathrm{mg}$, purity of $>98 \%$ with UHPLC, $t_{R} 25.32 \mathrm{~min}$, MeOH-0.1\% formic acid, 20:80, v/v ), compound 3 ( $1 \mathrm{mg}$, purity of > 98\% with UHPLC, $t_{R} 18.14 \mathrm{~min}$, $\mathrm{MeOH}-0.1 \%$ formic acid, 20:80, v/v), compound 4 (3 mg, purity of >97\% with UHPLC, $t_{R} 17.67 \mathrm{~min}, \mathrm{MeOH}-0.1 \%$ formic acid, 20:80, v/v), compound 5 (1 mg, purity of $>98 \%$ with UHPLC, $t_{R} 15.32 \mathrm{~min}, \mathrm{MeOH}-0.1 \%$ formic acid, 12:88, v/v ), compound 6 ( $2 \mathrm{mg}$, purity of $>98 \%$ with UHPLC, $t_{R} 19.14 \mathrm{~min}, \mathrm{MeOH}-0.1 \%$ formic acid, 10:90, v/v), compound 7 (3 mg, purity of > 98\% with UHPLC, $t_{R} 9.76 \mathrm{~min}$, $\mathrm{MeOH}-0.1 \%$ formic acid, 45:65, v/v).

Oleralignan A (1): Yellowish powder; $\mathrm{UV}\left(\mathrm{CH}_{3} \mathrm{OH}\right) \lambda \max 348,254 \mathrm{~nm}$; IR $(\mathrm{KBr}) v_{\max }$ 2934, 2850, 1740, 1565, 1518, 1452, $1212 \mathrm{~cm}^{-1} ;{ }^{1} \mathrm{H}$ NMR (600 MHz, DMSO- $\left.d_{6}\right)$ and ${ }^{13} \mathrm{C}$ NMR (150 MHz, DMSO- $d_{6}$ ), see Table S1 (in supplementary material); HR-ESI-MS $m / z 353.1021[\mathrm{M}-\mathrm{H}]^{-}$(calcd. for $\mathrm{C}_{20} \mathrm{H}_{17} \mathrm{O}_{6}{ }^{-}, 353.1031$ ).

\subsection{Anticholinesterase activity assay}

Acetylcholinesterase activities of compounds were assessed by a modified Ellman's method (Ellman et al. 1961). In a 96-well plate, $140 \mu \mathrm{L}$ PBS (0.1 M, pH = 8.0, containing $0.1 \mathrm{~mol} / \mathrm{L} \mathrm{NaH}_{2} \mathrm{PO}_{4}$ and $\left.\mathrm{Na}_{2} \mathrm{HPO}_{4}\right), 10 \mu \mathrm{L}$ DTNB $(15 \mathrm{mmol} / \mathrm{L}), 15 \mu \mathrm{L}$ $\operatorname{AChE}(0.2 \mathrm{U} / \mathrm{mL})$ and $20 \mu \mathrm{L}$ of sample solution serially diluted with methanol were mixed and incubated at $37^{\circ} \mathrm{C}$ for 10 minutes, then $10 \mu \mathrm{L}$ ATCI $(15 \mathrm{mmol} / \mathrm{L})$ was added and incubated at $20^{\circ} \mathrm{C}$ for 10 minutes. The absorbance was measured at $405 \mathrm{~nm}$. Eserine and methanol were used as positive and blank controls, respectively. The inhibition rate $(\%)$ of each sample AChE was calculated according to the following formula (Aktumsek et al. 2013): Inhibition activity $(\%)=\left[\left(\mathrm{A}_{\text {blank }}-\mathrm{A}_{\text {sample }}\right) / \mathrm{A}_{\text {blank }}\right] \times$ $100 \%$, in which, $\mathrm{A}_{\text {sample }}$ and $\mathrm{A}_{\text {blank }}$ were respectively the absorbance of the test compound and the blank control. The anticholinesterase activity was evaluated by the value of $\mathrm{IC}_{50}$ (means $\pm \mathrm{SD}, n=3$ ).

\section{Conclusion}

In the study, a novel lignan named oleralignan $\mathrm{A}$ and six known compounds were isolated from the water extract of $P$. oleracea $L$. The results of anticholinesterase activities assay showed that oleralignan A presented a higher anticholinesterase activity than others, with $\mathrm{IC}_{50}$ value of $58.31 \pm 0.23 \mu \mathrm{M}$.

\section{Supplementary material}

Supporting information can be found in the online version of this article.

\section{Disclosure statement}


The authors have no conflicts of interest to disclose.

\section{Acknowledgements}

This work was supported by the National Natural Science Foundation of China (grant number 82073990).

\section{References}

Aktumsek A, Zengin G, Guler GO, Cakmak YS, Duran A. 2013. Antioxidant potentials and anticholinesterase activities of methanolic and aqueous extracts of three endemic Centaurea L. species. Food Chem Toxicol. 55:290-296.

Bai Y, Zang XL, Ma JS, Xu GY. 2016. Anti-diabetic effect of Portulaca oleracea L. polysaccharideandits mechanism in diabetic rats. Int J Mol Sci. 17(8):1201.

Barton GM. 1968. Preparation and structure of dimethyl- $\alpha$-conidendrin-8-sulfonamide. Can J Chem. 46(7):1164-1165.

Davies HML, Jin Q. 2003. Intermolecular C-H activation at benzylic positions: synthesis of (+)-imperanene and (-)- $\alpha$-conidendrin. Tetrahedron Asymmetr. 14(7):941-949.

Ellman GL, Courtney KD, Jr VA, Featherstone RM. 1961. A new and rapid colorimetric determination of acetylcholinesterase activity. Biochem Pharmacol. $7(2): 88-90$.

Howes MJR, Houghton PJ. 2003. Plants used in Chinese and Indian traditional medicine for improvement of memory and cognitive function. Pharmacol Biochem Be. 75(3):513-527.

Karimi G, Hosseinzadeh H, Ettehad N. 2004. Evaluation of the gastric antiulcerogenic effects of Portulaca oleracea L. extracts in mice. Phytother Res. 18(6):484-487.

Lim YY, Quah EPL. 2007. Antioxidant properties of different cultivars of Portulaca oleracea. Food Chem. 103(3):734-740.

Loizzo MR, Menichini F, Conforti F, Tundis R, Bonesi M, Saab AM, Statti GA, Cindio Bd, Houghton PJ, Menichini F, et al. 2009. Chemical analysis, antioxidant, antiinflammatory and anticholinesterase activities of Origanum ehrenbergii Boiss and Origanum syriacum L. essential oils. Food Chem. 117(1):174-180.

Ma YF, Bao YR, Zhang WJ, Ying XX, Stien D. 2018. Four lignans from Portulaca oleracea L. and its antioxidant activities. Nat Prod Res. 34(16):2276-2282.

Meng YH, Ying ZM, Xiang Z, Hao D, Zhang WJ, Zheng Y, Gao YC, Ying XX. 2016. The anti-inflammation and pharmacokinetics of a novel alkaloid from 
Portulaca oleracea L. J Pharm Pharmacol. 68(3):397-405.

Mori K, Khlebnikov V. 1993. Carotenoids and degraded carotenoids, VIII: Synthesis of (+)-dihydroactinidiolide, (+)- and (-)-actinidiolide, (+)- and (-)-loliolide as well as (+)- and (-)-epiloliolide. Liebigs Ann Chem. 1993:77-82.

Nayaka HB, Londonkar RL, Umesh MK, Tukappa A. 2014. Antibacterial attributes of apigenin, isolated from Portulaca oleracea L. Int J Bacteriol. 2014(2014):175851. Rashed AN, Afifi FU, Disib AM. 2003. Simple evaluation of the wound healing activity of a crude extract of Portulaca oleracea L. (growing in Jordan) in Mus musculus JVI-1. J Ethnopharmacol. 88(2-3):131-136.

Shen H, Tang G, Zeng G, Yang YJ, Cai XW, Li DL, Liu HC, Zhou NX. 2013. Purification and characterization of an antitumor polysaccharide from Portulaca oleracea L. Carbohyd Polym. 93(2):395-400.

Salleh WMNHW, Ahmad F, Yen KH, Zulkifli RM. 2016. Anticholinesterase and anti-inflammatory constituents from Beilschmiedia pulverulenta kosterm. Nat Pro Sci. 22(4):225-230.

Tandon A, Rogaeva E, Mullan M, St George-Hyslop PH. 2000. Molecular genetics of alzheimer's disease: the role of $\beta$-amyloid and the presenilins. Curr Opin Neurol. 13(4):377-384.

Teixeira MC, Carvalho IS, Brodelius M. 2010. Omega-3 fatty acid desaturase genes isolated from purslane (Portulaca oleracea L.): expression in different tissues and response to cold and wound stress. J Agric Food Chem. 58(3):1870-1877.

Uddin MK, Juraimi AS, Ali ME, Ismail MR. 2012. Evaluation of antioxidant properties and mineral composition of purslane (Portulaca oleracea L.) at different growth stages. Int J Mol Sci. 13(8):10257-10267.

Wan C, Yuan T, Cirello AL, Seeram NP. 2012. Antioxidant and alpha-glucosidase inhibitory phenolics isolated from highbush blueberry flowers. Food Chem. 135(3):1929-1937.

Xiu F, Li XT, Zhang WJ, He F, Ying XX, Stien D. 2019. A new alkaloid from Portulaca oleracea L. and its antiacetylcholinesterase activity. Nat Prod Res. 33(18):2583-2590.

Xu WZ, Jin HZ, Zhang WD, Fu JJ, Hu XJ, Zhang W, Yan SK, Shen YH. 2008.

Studies on the chemical constituents of Daphne pedunculata. Chem Nat Compd. 44(6):771-772. 
Yang X, Ying ZM, Liu HR, Ying XX, Yang GL. 2019. A new homoisoflavone from Portulaca oleracea L. and its antioxidant activity. Nat Prod Res. 33(24):3500-3506.

Yang X, Zhang WJ, Ying XX, Stien D. 2018. New flavonoids from Portulaca oleracea L. and their activities. Fitoterapia. 127:257-262.

Yazici I, Türkan I, Sekmen AH, Demiral T. 2007. Salinity tolerance of purslane (Portulaca oleracea L.) is achieved by enhanced antioxidative system, lower level of lipid peroxidation and proline accumulation. Environ Exp Bot. 61(1):49-57.

Zhao CC, Zhang CG, He F, Zhang WJ, Leng AJ, Ying XX. 2019. Two new alkaloids from Portulaca oleracea L. and their bioactivities. Fitoterapia. 136:104166.

Zheng GY, Peng H, Li M, Gu W, Chen Z, Ling CQ. 2017. Antihepatocarcinoma

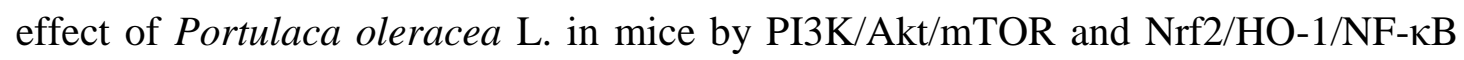
pathway. Evid Based Compl Alt. 2017(1):1-11.

Zheng JX, Zheng Y, Zhi H, Dai Y, Wang NL, Fang YX, Du ZY, Zhang K, Wu LY, Fan M. 2014. $\gamma$-lactone derivatives and terpenoids from selaginella uncinata and their protective effect against anoxia. Chem Nat Compd. 50(1):366-369.

Zhou HY, Hong JL, Shu P, Ni YJ, Qin MJ. 2009. A new dicoumarin and anticoagulant activity from Viola yedoensis Makino. Fitoterapia. 80(5):283-285. 